\title{
Post-occupancy Evaluation and Thermal Comfort: State of the Art and New Approaches
}

\author{
Elke Gossauer and Andreas Wagner
}

\begin{abstract}
Building occupants are a valuable source of information on building performance as well as indoor environmental quality and their effects on comfort and productivity. A large number of different studies have been carried out over recent decades focusing on various aspects of the broad field of comfort, well-being and health at workplaces. Two main methodical approaches can be identified analysing the history of comfort research: laboratory tests in climate chambers, and field tests in running buildings. Advantages and disadvantages of both approaches are pointed out in this paper and some of the most well-known studies from Europe and the US are described with respect to their specific objectives and methodologies. No difference is made between pure comfort field studies and more general post-occupancy evaluations because the borderline is vague in most cases and the purpose of this paper is to collect as much useful information as possible on comfort research methods. A current study on overall comfort at workplaces introduces a new multivariate approach, including building-related and further contextual parameters.
\end{abstract}

Keywords - comfort research methods; post-occupancy evaluation; workplace; comfort parameters; thermal comfort; indoor climate; general satisfaction

\section{INTRODUCTION}

The question of what constitutes a 'comfortable' thermal environment has preoccupied people ever since they have had to cope with indoor climate conditions. Important aspects have been, for example, building-related illnesses (Kröling, 1985), the development or planning of air-conditioning systems, normative requirements and design guidelines. Energy efficiency in buildings, which is addressed in the European Energy Performance of Buildings Directive of 2001, adds significant weight to comfort and workspace quality issues. On the one hand, energy savings with conventional cooling or 
air-conditioning systems must not lead to less comfortable indoor conditions. On the other hand, new energy efficient building concepts and technologies featuring natural ventilation and passive cooling require a revision of comfort standards that were developed for air-conditioned buildings only. Further, appropriate policies are needed to combine excellent energy building performance and high workspace quality in commercial buildings under different climates.

The question of comfort has always been approached by tests with people in order to include subjective votes and correlate them with measured climate parameters. While standards on thermal comfort were exclusively based on laboratory tests for a long time, the demand for field studies gradually arose. For example, building monitoring and surveys were meant to improve the dialogue between all partners of the design and building process and enhance their responsibility for the performance of the building (Bordass and Leaman, 2005). Further, the interdependence between indoor and outdoor climate was investigated in running buildings to test the applicability of the existing standards and predictive tools (ISO 7730, 2005). It became obvious that different results are obtained by testing people in their real working environment when this is not airconditioned. Cross-correlations could be shown in the prediction of air quality, overall comfort and self-estimated productivity, and assumptions for comfort criteria (clothing value, metabolic rate) did not coincide with those given in the standards (Brager and de Dear, 1998; de Dear, 2004; Wagner et al, 2006). The development of the resulting adaptive comfort models is addressed in detail in the paper by Humphreys, Nicol and Raja (Chapter 3 of this volume).

Besides thermal comfort parameters a lot more information about indoor environment quality can be obtained by field tests. Almost every building has performance deficiencies to some extent, particularly during and directly after the commissioning phase. Technical equipment for heating, cooling, ventilating, air conditioning and lighting has to be adjusted and adapted to occupants' needs, which could be done by post-occupancy evaluation alternatively, or in parallel, to monitoring relevant data points. Post-occupancy evaluation is therefore a good opportunity to create a feedback loop for architects, planners and building industry professionals in order to learn how different building design features and technologies affect occupant comfort, satisfaction and productivity.

Despite an increasing interest in building performance assessment and postoccupancy evaluation, the results of such assessments are not routinely available. Further research on methodical approaches is necessary to finally implement post-occupancy evaluation as a standardized procedure into facility management. This paper gives an overview and evaluation of studies that have been carried out over recent decades in terms of objectives, methods applied and results. Although different definitions for postoccupancy evaluation and field studies of thermal comfort can be found in the literature (for example Nicol and Roaf, 2005), it is often difficult to draw a clear line between them in terms of purpose and methodology. Therefore in this paper post-occupancy evaluation is understood in a broad sense as an evaluation by people in buildings on the basis of questionnaires of various extent and generally in connection with physical measurements of different levels of detail. 


\section{BRIEF HISTORY OF OCCUPANT EVALUATION AND COMFORT DEFINITIONS}

The spectrum of scientific disciplines working on thermal comfort has been diverse, ranging from environmental psychologists dealing with perceived comfort and productivity in buildings (Cooper, 2001; de Dear, 2004), to engineers who always dominated research in this field. The first project on indoor environmental psychology and ergonomics had the aim of raising workforce productivity by manipulating the physical environment of workers. In the 1920s experiments with lighting levels were made in Hawthorne, US, by the National Research Council and it was found that any changes had an impact on productivity (Thommen, 2002). One of the results of these early experiments was that placebo changes also had a psychological effect on the workers. Therefore the assumption was made, that any positive intervention of the management was more important for productivity improvement than the actual environmental conditions. Probably due to this reason the issue was passed from psychologists to engineers, architects and end-users (Canter et al, 1975).

Single studies have been undertaken over the years, for example the Bedford study in 1936 (Bedford, 1936), but all in limited contexts. In 1963, the Royal Institute of British Architects (RIBA) published its Plan of Work for Design Team Operation (Bordass, 2005), which included occupant surveys and their feedback, because already at that time the need for evaluation in real existing buildings was recognized. This attempt was unfortunately withdrawn in 1972, probably because nobody was found to take over the costs of this service (Cooper, 2001).

The issue of building monitoring arose again in the 1970s, but then mainly due to problems of building-related illnesses (Kröling, 1985). At the same time the use of air conditioning (Brager and de Dear, 2003) and new materials was growing, which brought up the necessity of 'quantifying' comfort. It was Fanger in the 1970s (Fanger, 1970) who started systematic research on thermal comfort and the effect of clothing and activity upon the human heat exchange for that purpose. Since the 19th century, the understanding of comfort had only been related to the factors of light, heat and ventilation (Brager and de Dear, 1998). The newly developed heat balance models of Fanger (1970) and Gagge et al (1986) viewed people as passive recipients of thermal stimuli. This implied a quite simple cause-and-effect approach, where the physical boundary conditions of the indoor environment influenced the human physiology and therefore the possible conditions of subjective comfort or discomfort.

The succeeding standards, based on the heat balance model of the human body and derived from extensive experiments in climate chambers, were appropriate for buildings with air conditioning, though they suggested that they were applicable for all building types, population and climates (Fanger, 1970). As a result, clear limits for the indoor climate were given that had to be met by the heating, ventilation and air-conditioning (HVAC) systems.

Field studies at that time already recognized the interaction between people and their surroundings, for example by changing their clothes, their work speed or opening/closing their windows (Nicol and Humphreys, 1973) (Figure 7.1). This already implied the theory that people can adapt to their thermal environment. 


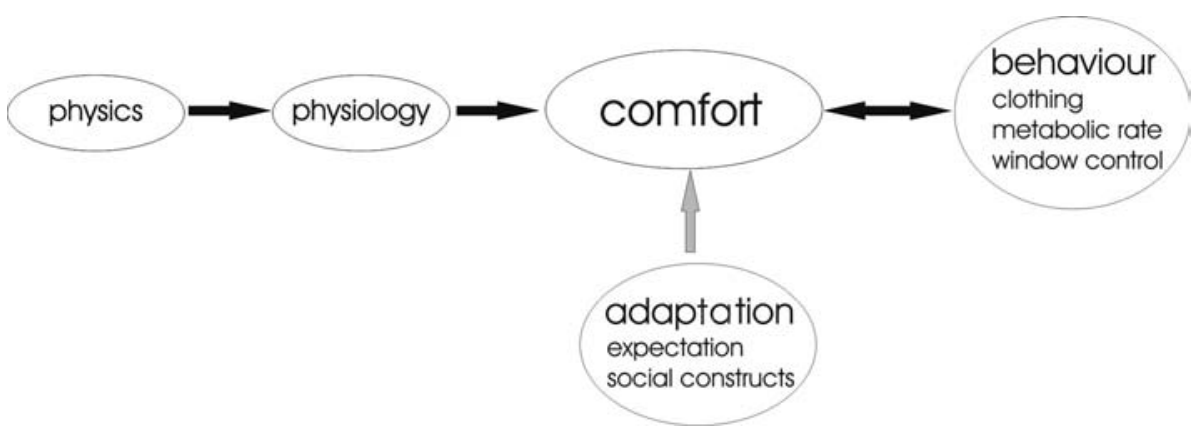

Source: Elke Gossauer

FIGURE 7.1 Cause-and-effect approach for field studies of thermal comfort during the 1970s

The 1980s brought further changes in the building industry and other attempts to establish post-occupancy evaluation were made in several countries. There was great competition within the building industry to improve the speed and quality of the building process and to reduce the costs of building materials. The HVAC industry grew rapidly and also new requirements of information technology had to be adopted. Since then, buildings have been used more intensively and are strongly influenced by social, technical and marketing changes.

One of the effects of this was the discussion and extension of the definition of thermal comfort. For example Cooper (1982) claimed that comfort standards were 'social constructs, which reflect the beliefs, values, expectations and aspirations of those who construct them'. In the 1980s it was argued that thermal comfort is a multivariate phenomenon that is influenced by behaviour (clothing, activity and ventilation rate) and expectations, as well as by environment and memory (Brager and de Dear, 2003) (Figure 7.2).

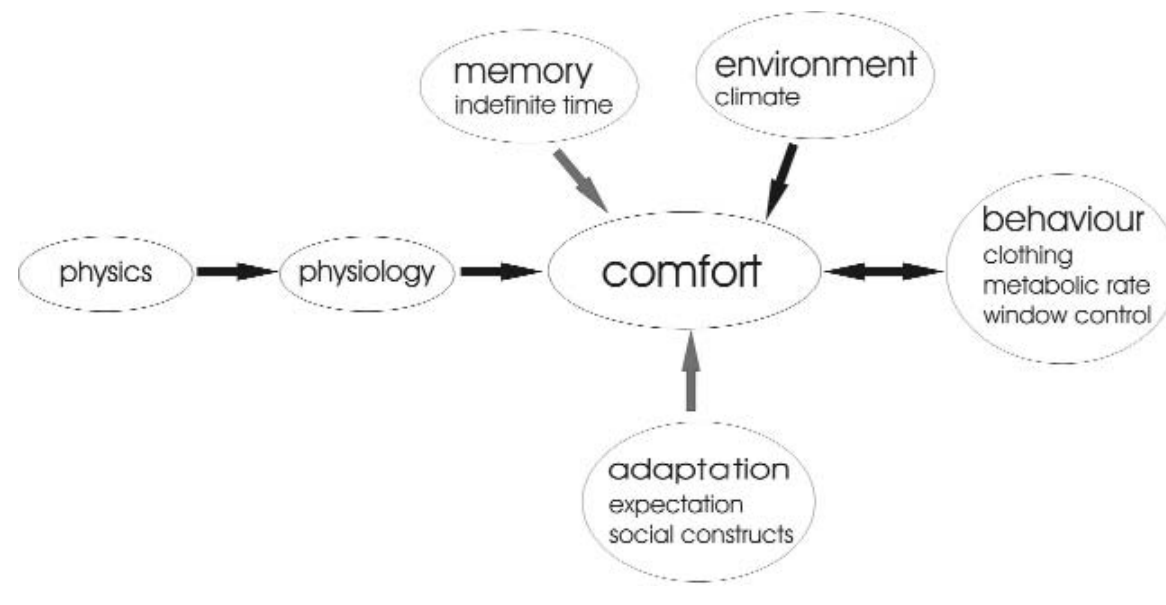

Source: Elke Gossauer

FIGURE 7.2 Cause-and-effect approach for field studies of thermal comfort in the 1980s 


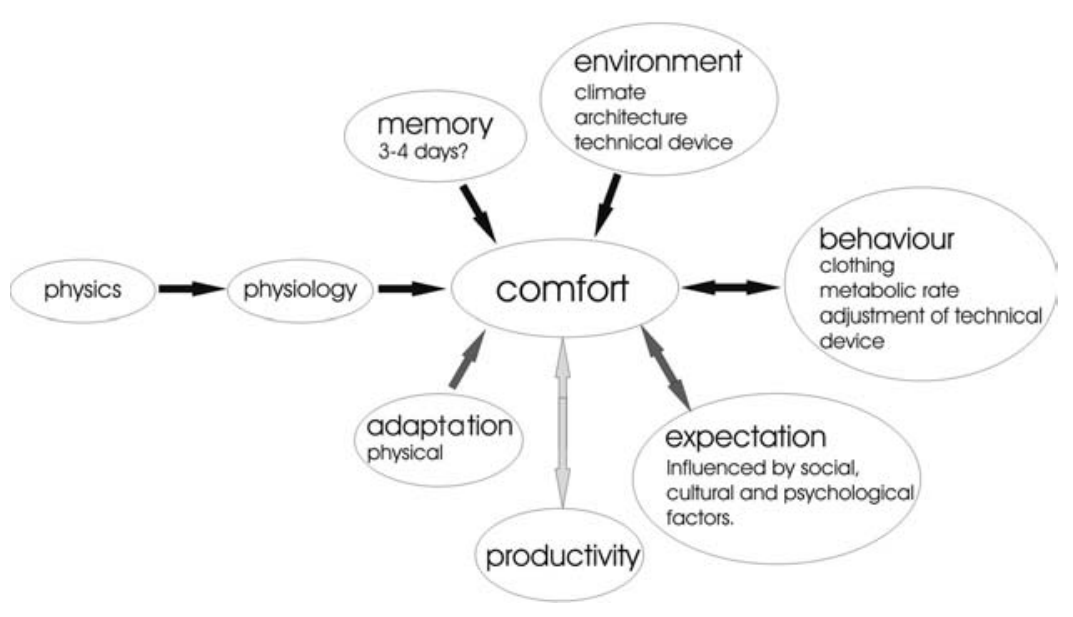

Source: Elke Gossauer

FIGURE 7.3 Cause-and-effect approach for field studies of thermal comfort in the 1990s

In the ASHRAE standard of 1992 the definition of comfort was established. Comfort was defined as 'the condition of mind that expresses satisfaction with the thermal environment'. With the growing complexity of the indoor environment, it became almost impossible to 'measure' comfort directly (Brager and de Dear, 2003). Besides measuring the physical variables that influence the body's heat balance, questions about thermal sensation and preference were introduced, both in the climate chamber and in the field. Conclusions about satisfaction or dissatisfaction of people were derived from that. With expanding research, further topics like architecture and technical devices, as well as social, psychological and cultural factors were added and confirmed (Nicol and Kessler, 1998) (Figure 7.3).

In the 1990s, interest rose in finding correlations between different indoor parameters and the perception of health, comfort and productivity at work. More and more field surveys, mostly independently targeted, were realized in different countries to analyse different comfort parameters and how people react to changes of their indoor environment (Leaman and Bordass, 2001). A very good review of projects until 1997 is given in the literature review of Brager and de Dear (1998).

Today a stronger emphasis is given to psychological parameters and their impact on satisfaction and productivity, but also to possibilities of energy saving in buildings while maintaining a high comfort standard. Besides the physical parameters, the following criteria have been identified to have a strong impact on occupant satisfaction with temperature (de Dear et al, 1997):

adjustments of clothing, blinds, windows, heating and so on;

- physiological acclimatization and psychological expectation;

- thermal expectation formed by the past thermal history, weather forecast and so on; and

- time of exposure and non-thermal factors such as available or performed control. 
Although many studies are not mentioned in this review, this brief history of evaluation methods and investigated topics clearly illustrates the (growing) complexity of the interrelations between building-related factors and their influences on occupants' (thermal) comfort. Yet even now, many correlations have not been found or confirmed. Multidisciplinary work is therefore necessary and multiple methods have to be connected. Both possible approaches for the evaluation of (thermal) comfort in buildings - research in the laboratory and in the field - are discussed in more detail below.

\section{WHAT ARE THE DIFFERENCES OF OCCUPANT EVALUATION IN THE LABORATORY AND IN THE FIELD?}

Thermal comfort studies have been carried out intensively since the 1970s under laboratory conditions. Field studies have been conducted too, but with different emphases, as described above. In climate chambers, physiological and psychological reactions of human subjects to climate parameters, such as air temperature, radiant temperature, humidity and air velocity, can be reproducibly investigated under controlled conditions. Together with a clothing value and the metabolic rate, Fanger validated his predicted mean vote-percentage of people dissatisfied (PMV-PPD) model (Fanger, 1970) with these experiments for defined indoor conditions. This model forms the basis of the ISO 7730. The model implies a steady-state human heat balance, which is independent of external climate parameters. It was not possible for the subjects to change the climate conditions they were experiencing or their clothing (Brager et al, 2004).

Laboratory-based studies are likely to ignore contextual influences that can weaken the meaning of responses to a given set of thermal conditions. From chamber studies, it has not yet been possible to assess how dissatisfactions from multiple sources are combined because they are masked. Moreover, climate chambers generally do not adequately reflect a workspace environment that occupants experience in real buildings.

Because of increasing doubts about the external validity and relevance of climate chamber results for building occupants over recent decades, ASHRAE commissioned a series of thermal comfort studies in the 1990s. The aim was to validate the findings of experiments in climate chambers and the resulting standards for HVAC systems in the field in a variety of climatic contexts around the world (de Dear, 2004).

Occupants' responses to conditions in real buildings may be influenced by a range of complex factors that are not accounted for in the heat balance models. Field studies consider the whole indoor environment of the surveyed people, depending on the survey methods. Accordingly it is possible to analyse how different building types and technologies react to the outdoor climate and how this is perceived by the building occupants.

A major problem of field studies is that environmental conditions in most buildings are transient and difficult to measure accurately, together with the occupants' votes. Therefore 'errors of the input data give rise to errors in the relationship in statistical analysis' (Humphreys and Nicol, 2000). Care has to be taken in generalizing the results of one survey from statistical analysis, even if the circumstances in other buildings are similar.

Another challenge of a multicriteria approach in real buildings is that the correlations between multiple parameters still have to be found and validated. This is similar to the 
analysis of the sick building syndrome and productivity research. However, more recent and systematically performed field studies and experiments give the basis for quantifying the specific causal mechanisms concerning thermal comfort and adaptation of occupants. One example is the adaptive comfort model that gives a relation between the predictors for thermal comfort known from the laboratory and the outdoor temperature (Brager and de Dear, 1997; de Dear, 2004).

With ongoing evaluation in the field, it was becoming increasingly evident that the explanation of thermal comfort is not as distinctive as thought on the basis of research in the laboratory. Recent studies report that other comfort parameters, such as indoor air quality or visual and acoustic conditions, correlate with thermal and overall comfort and well-being (Roulet et al, 2006a). The ability to control indoor environmental parameters influences satisfaction with temperature. Differences in the perception of noise and sounds were found in relation to social and cultural statuses and different relations to the source. For further analysis of thermal comfort, discussion must be widened beyond the experimental environment (climate chamber or running building) to include other aspects of experimental design.

\section{CLASSIFICATION OF SURVEY PROCEDURES AND RATING SCALES}

Brager and de Dear (1998) describe three classes of thermal comfort studies:

- Class I: All sensors and procedures are in 100 per cent compliance with the specifications in ASHRAE 55 (ASHRAE, 2004) and ISO 7730. Measurements at three heights above floor level with laboratory grade instrumentation are required. This procedure allows a careful examination of the effects of non-uniformities in the environment as well as a comparison between buildings.

- Class II: All physical environmental variables necessary for calculating PMV and PPD indices are measured and collected at the same time and place when and where the thermal questionnaires are administered, most likely at one height. This allows an assessment of the impact of behavioural adjustment and control on subjective responses.

- Class III: This is based on simple measurements of indoor temperature and possibly relative humidity at one height above the floor. The physical measurements can possibly be asynchronous with subjective measurements (questionnaire with rating scales).

Most of the field studies conducted over recent decades have been Class III studies. The quality does not necessarily allow explanatory analyses by extensive statistics. The analysis is limited by its ability to determine causal mechanisms, but gives a good and generally quick overview over the situation and some correlations within and between the buildings. Particularly in naturally ventilated buildings, measurements and the filling of the questionnaires should take place at the same time because there are rooms that might have temporarily or spatially non-uniform thermal conditions.

Rating scales for thermal sensation have been in use for over 50 years, others even longer. Details for performing measurements in the field are given in the existing 
standards (ASHRAE and ISO 7730). Measurement parameters and survey questions are mostly adopted from research in the laboratory. With the ASHRAE scale (in the US) a person is thermally comfortable at the neutral point of no thermal sensation, and so thermal comfort is here defined as the absence of thermal discomfort. The other scale that is commonly still in use is the Bedford scale (in the UK). The Bedford scale confounds warmth and comfort, which makes it less applicable when compared to the ASHRAE. Other scales are also used.

\section{MAIN STUDIES AND THEIR OBJECTIVES}

Over the last two decades, field studies have been performed with different objectives and therefore by means of partly varying methodologies, mainly by researchers from universities. However, companies like BREEAM (BRE's Environmental Assessment Method) in Britain and LEED (Leadership in Energy and Environmental Design) in the US were established to commercially investigate comfort as part of the sustainability of buildings (benchmarking of 'green buildings').

In 1981 Building Use Studies (BUS) was founded in London as an independent consultancy (Bordass and Leaman, 2005). Since then BUS has examined how buildings perform, particularly from the viewpoints of building occupants. The company has carried out post-occupancy evaluations in the UK and around the world, investigating occupants' health, perceived comfort (including personal control) and self-estimated productivity. One of the prevalent objectives has been a benchmarking of the analysed buildings. One of the BUS projects was an evaluation of 40 office buildings, comparing the self-estimated productivity of occupants between naturally ventilated and air-conditioned buildings (Leamann and Bordass, 1999) in connection with the depth of buildings and office zones respectively. Feedback to the users is seen as one of the most important issues of BUS building monitoring. Many outputs from BUS (though not commissioned consultancy reports) are available via the website, www.usablebuildings.co.uk. BUS survey methods are available under licence and are in use worldwide.

The interest in differences between naturally ventilated and air-conditioned buildings is almost as old as air conditioning itself. Research topics have been, for example, building-related illness, perception of thermal comfort and indoor air quality and later on, self-estimated productivity. At the end of the 1990s a series of thermal comfort studies was performed (Nicol and Kessler, 1998; Rowe, 1998) that mainly investigated the influences of the ventilation type of the building, the proximity of occupants to windows and their access to natural ventilation facilities on the rating on thermal and overall comfort. Research by de Dear and Brager (De Dear et al, 1997) revealed that occupants of naturally ventilated buildings are comfortable in a wider range of temperatures than occupants of buildings with centrally controlled HVAC systems (Mendell, 1993). The comparison of different field studies in four countries led to the development of the adaptive comfort model. However, the exact influence of personal control in explaining these differences could only be hypothesized because of the limits of the existing field study data that formed the basis of that research.

Therefore further projects were initialized to quantitatively investigate how personal control of operable windows in office settings influences local thermal conditions and 
TABLE 7.1 Post-occupancy studies mainly related to research in thermal comfort and its predictive parameters

\begin{tabular}{|c|c|c|c|}
\hline PROJECT NAME & YEAR & BUILDING TYPES & OBJECTIVES \\
\hline SCATS & 1997-2000 & $\begin{array}{l}\text { Naturally ventilated (NV), } \\
\text { air-conditioned }(\mathrm{AC})\end{array}$ & $\begin{array}{l}\text { Correlation between comfort temperature } \\
\text { and indoor/outdoor temperatures, } \\
\text { behavioural analyses }\end{array}$ \\
\hline PROBE & 1995-2002 & NV, AC, mixed & $\begin{array}{l}\text { Energy and environmental } \\
\text { performance, thermal comfort, } \\
\text { occupant satisfaction, feedback }\end{array}$ \\
\hline RP-1161 & Unknown & NV, AC & $\begin{array}{l}\text { Influence of personal control on } \\
\text { thermal comfort, self-controlled } \\
\text { acquisition of physical and } \\
\text { subjective data }\end{array}$ \\
\hline
\end{tabular}

occupant comfort (PROBE, 1999; Nicol and McCartney, 2000; Bischof et al, 2003). Their aim was to disentangle the precise effect of personal control from other potential explanations for people's acceptance of more variable thermal conditions. The data showed that occupants with different levels of personal control had significantly diverse thermal responses, even when they experienced the same thermal environments and clothing and activity levels.

Another principal concern of those studies was to relate thermal comfort and the comfort temperature to the indoor and outdoor climate and to compare them with the PMV index (Table 7.1). The data of all three studies include a wide range of subjective and environmental measurements and the database (with both environmental and subjective data) has mainly been used to define an adaptive algorithm but also for the analysis of technical and environmental performance of the buildings, occupant satisfaction and productivity (Leamann and Bordass, 1999). The projects also showed a more systematic approach to the surveys.

Two projects investigating the issue of sick building syndrome were realized in Germany and Switzerland (Table 7.2). Again, the influence of technical features (natural ventilation or air conditioning) was one of the main interests.

In the ProKlima study (Bischof et al, 2003), 14 German office buildings were evaluated with regard to sick building syndrome in air-conditioned and free-running

TABLE 7.2 Post-occupancy studies mainly related to research in the field of sick building syndrome

\begin{tabular}{llll}
\hline PROJECT NAME & YEAR & BUILDING TYPES & OBJECTIVES \\
\hline ProKlima & NV, AC & $\begin{array}{l}\text { Contribution of the indoor climate, } \\
\text { energy concept and psychological } \\
\text { factors to the illness symptoms and } \\
\text { thermal comfort }\end{array}$ \\
HOPE & NV, AC & $\begin{array}{l}\text { Benchmarking of 'healthy' and } \\
\text { energy efficient buildings, input } \\
\text { into CEN standards }\end{array}$ \\
\hline
\end{tabular}


buildings. The study, which was realized by six interdisciplinary German research groups, was the first one with a distinct experimental design and systematics in the field of sick building syndrome. By means of a questionnaire, physical measurements and medical investigations, the impacts of the indoor climate, as well as psychological factors, on illness symptoms were evaluated. Hellwig (2005) further analysed the existing data to reveal correlations between ventilation strategies and thermal comfort.

The objective of the Health Optimisation Protocol for Energy-efficient Buildings (HOPE) project was to define a set of qualitative (prescriptive) and quantitative (measurable) performance criteria for healthy and energy efficient buildings in different European climates. Results should directly be incorporated into European Committee for Standardization (CEN) standards and in this context be used as guidelines for improving building performance. The study mainly produced a coarse benchmarking of buildings (green, yellow, red and black labels) by using basic statistics, for example, frequency distributions and assigning a British Standards Institution (BSI) Index in connection with air-conditioned and naturally ventilated buildings by the analysis of variance. Data are still being analysed (Bordass and Leaman, 2004; Roulet et al, 2006 b;HOPE, 2006).

A recently growing interest of post-occupancy evaluation is the quality benchmarking of buildings as a feedback instrument to architects, engineers and industry, and also to the occupants (Table 7.3). For this purpose the Center for the Built Environment (CBE) in Berkeley has used indoor environment quality (IEQ) surveys since 1996 to systematically collect and archive occupant responses in buildings. Their work includes building diagnoses, evaluation of new building technologies, identification of new trends in building performance, and benchmarking the quality of individual buildings against the population of similar buildings. By 2005 surveys in more than 70 buildings had been finished (including office buildings, laboratories, banks and courthouses) and a rapidly growing database of standardized survey data was established that is used for benchmarking (Zagreus et al, 2004) and advanced data analysis. The IEQ surveys are often part of a post-occupancy evaluation process in which the design and operation of a building is assessed. Different applications are available, for example, for pre- or post-analysis of occupants moving into a building, correlations of occupants' ratings with physical measurements, and evaluation of clients' design objectives. Feedback to building managers, occupants or industry partners is given by means of a self-controlled reporting tool.

TABLE 7.3 Post-occupancy studies for benchmarking and performance feedback

\begin{tabular}{llll}
\hline ORGANIZATION & YEAR & BUILDING TYPES & OBJECTIVES \\
\hline CBE, Berkeley & Since 1996 & NV, AC, mixed & $\begin{array}{l}\text { Diagnosis of problems, } \\
\text { evaluation of new building } \\
\text { technologies, quality } \\
\text { benchmarking }\end{array}$ \\
CCC & Since 2001 & $\begin{array}{l}\text { Feedback on the performance } \\
\text { of industry products for buildings }\end{array}$ \\
BREEAM, LEED & Unknown year of & Benchmarking of 'green' buildings \\
& start until today & \\
\hline
\end{tabular}


In 2001 the Confederation of Construction Clients (CCC) was formed in the UK for better cooperation between clients and their suppliers. CCC started a research project developing a feedback system that should help to obtain better information about the performance of completed buildings. The activities of BREEAM and LEED, detailed above, also form a contribution.

\section{APPROACHES TO POST-OCCUPANCY EVALUATION IN DIFFERENT STUDIES}

In all studies a crucial point was to establish from the outset is good contacts with all persons in authority to ensure cooperation between occupants and the project team. The procedures followed during a majority of building evaluations (Figure 7.4) are outlined below.

An inspection of each building is necessary to provide basic data of the buildings and their environment. This is commonly followed by interviews with the building management, from which information on building energy performance (and other issues) is collected. As a third step a questionnaire is distributed to the occupants - either on paper or via internet or intranet (either web or email) - that gathers information on how the internal environment is perceived and rated. Measurements of physical parameters are performed according to the different methods outlined above.

De Dear et al (1997) collected and analysed a database (ASHRAE RP-884) consisting of data derived from thermal comfort field experiments in 160 buildings (mainly commercial offices) from four continents, which were either naturally ventilated (45) or had centrally controlled HVAC systems (111). The number of investigated buildings per study ranged from 1 to 16 . The occupant samples per building lay between 6 and 380 persons, and approximately 22,000 comfort questionnaires were completed in total.

Some studies were divided into summer and winter surveys. One requirement of the surveys was that the occupants' microclimate at their workplace be simultaneously monitored. Therefore a detailed set of indoor climate and thermal comfort data is available for each building.

In most of the surveys the findings were rated on the ASHRAE seven-point scale. Sometimes the Bedford Scale was also used. Only in some of the studies was additional information requested on either thermal acceptability or preference, and seldom for both. Where preferences were addressed, three-point or five-point scales where used to rate them. Clothing values were either estimated by ISO 7730 or ASHRAE 55, sometimes taking into account the occupant's chair.

The ASHRAE-RP-1161 project was conducted in a totally naturally ventilated building in Britain. The office layout was mainly open-plan, with varying levels of direct or indirect individual control, based on proximity of occupants to the operable windows. Continuous measurements of the microclimate at each workstation were taken and the occupants had to fill in a web-based questionnaire that was developed at the CBE. Both a general background survey and a short repetitive survey were conducted. The questionnaire for general background was administered to all 230 occupants and included basic demographics, personal workplace characteristics and aspects such as individual environmental control opportunities, window operation and satisfaction with various 
environmental attributes. The return rate was around 40 per cent, that is, the norm for web-based surveys (Zagreus et al, 2004).

In a second step, 38 persons (24 females, 14 males), all of them volunteers, had to fill in a short repetitive questionnaire evenly distributed over each day after having been at their workstation for at least 30 minutes. The survey was linked with indoor climate

\section{Buildings}

- of architectural interest

- $\quad$ of technical interst

- $\quad$ accessability (contact to building managers, facility managers etc.

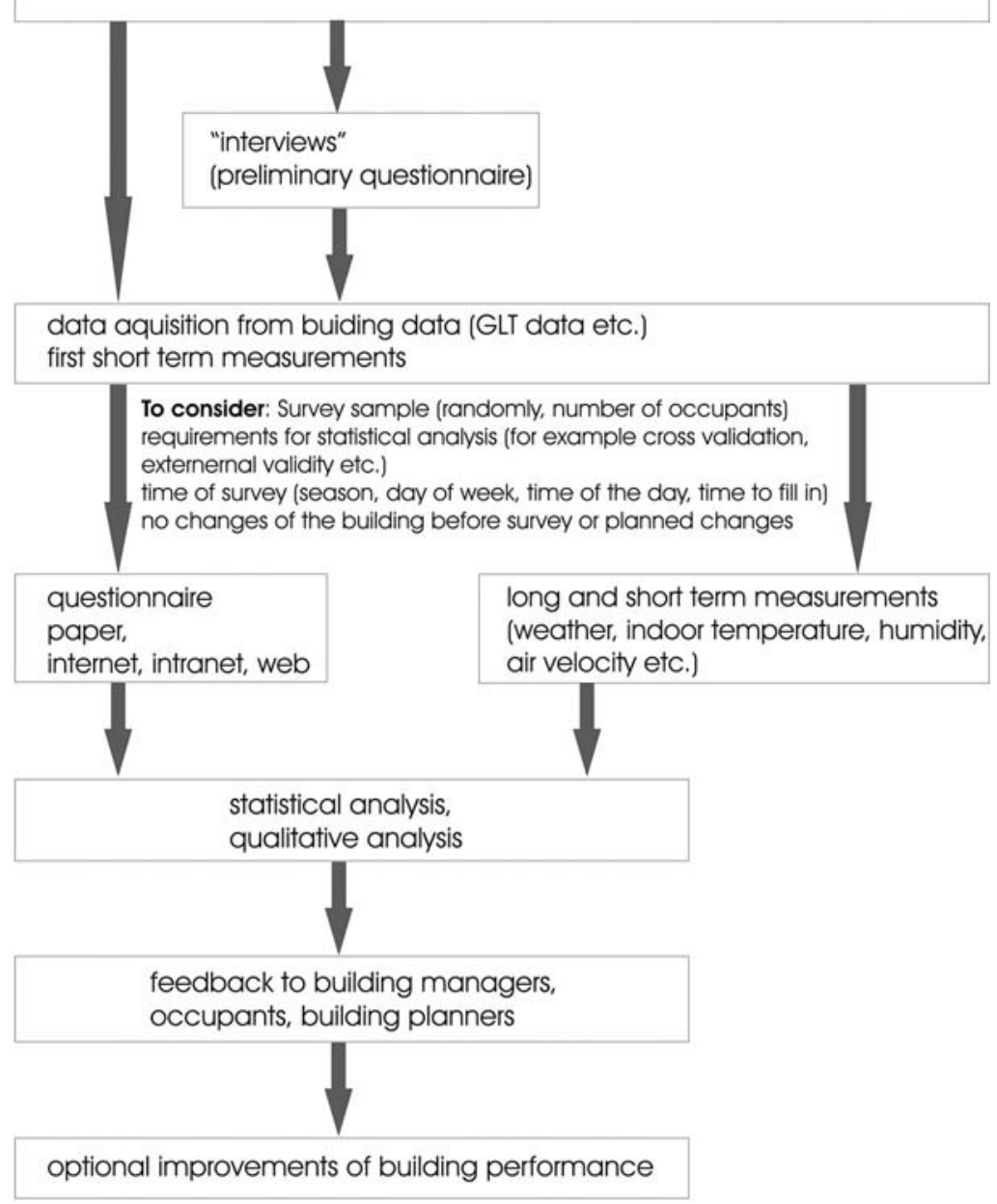

Source: Elke Gossauer

FIGURE 7.4 General procedure of building surveys 
TABLE 7.4 Field experiment methodology of ASHRAE RP-1161

\begin{tabular}{|c|c|c|}
\hline & BACKGROUND STUDY & DETAILED STUDY \\
\hline $\begin{array}{l}\text { Physical } \\
\text { measurements }\end{array}$ & $\begin{array}{l}\text { Continuous measurements of } \\
\text { indoor climate conditions: } \\
\text { temperature and humidity } \\
\text { in different zones within } \\
\text { the building }\end{array}$ & $\begin{array}{l}\text { Continuous measurements of } \\
\text { workplace climate conditions: } \\
\text { dry-bulb temperature, globe } \\
\text { temperature, air velocity, } \\
\text { plus nearby meteorological } \\
\text { station }\end{array}$ \\
\hline Web-based survey & $\begin{array}{l}\text { Once, before detailed survey, } \\
\text { seasonal impressions, } \\
10-15 \text { minutes long }\end{array}$ & $\begin{array}{l}\text { Several times/day, } \\
\text { current impressions, } \\
1-2 \text { minutes long }\end{array}$ \\
\hline Subject pool & $\begin{array}{l}\text { Entire building occupant } \\
\text { population }\end{array}$ & 38 voluntary subjects \\
\hline $\begin{array}{l}\text { Duration and } \\
\text { frequency }\end{array}$ & $\begin{array}{l}\text { Two-week period during } \\
\text { winter and summer; } \\
\text { subjects took the survey } \\
\text { only once, at their convenience, } \\
\text { during that period }\end{array}$ & $\begin{array}{l}\text { Two-week period in each } \\
\text { of the two seasons immediately } \\
\text { following the background study; } \\
\text { subjects took the survey } \\
\text { repetitively during that } \\
\text { period, on average two to three } \\
\text { times per day }\end{array}$ \\
\hline
\end{tabular}

measurements that were taken with very similar instrumentation to that used in laboratories. Measurements and short repetitive surveys took place over two weeks in winter (February and March 2003) and two weeks in summer (September and October 2002). The occupants had to fill in a list of clothing options and five different descriptions of office tasks to describe their activity during the previous 30 minutes for the calculation of the clothing values (including the chair) and the metabolic rate. In addition to traditionally used questions, newly developed questions about thermal variability, air movement, window and blind patterns and other environmental adjustments, as well as energy level and mental alertness were added. Over 1000 survey responses in each of the two main seasons were collected and the subjective and physical measurements were cross-linked. In Table 7.4 the methodology of the surveys and measurements of the ASHRAE RP-1161 project are shown.

The SCATs (Smart Controls and Thermal Comfort) Project included the evaluation of 26 office buildings situated in England, Sweden, Portugal, Greece and France (Nicol and McCartney, 2000) (Table 7.5). Each partner of the research team chose five buildings for the surveys. The aim was to have some 200 subjects per country over 12 months of surveys, but this was not always achieved ( 850 people finally took part in the surveys). The number of subjects per building taking part in the full monthly surveys (Level 1) varied from 4 to 111. A background survey was conducted in each of the buildings in which all occupants were asked to fill in a paper questionnaire. The intention of this questionnaire was to explore the attitude of the subjects to the building they were working in and to give information about their job, the working environment, individual control possibilities of the 
TABLE 7.5 Field experiment methodology of the SCATs project

\begin{tabular}{|c|c|c|}
\hline & BACKGROUND STUDY & DETAILED STUDY \\
\hline \multirow[t]{2}{*}{ Physical measurements } & & Transverse study: \\
\hline & & $\begin{array}{l}\mathrm{CO}_{2} \text {, globe temperature, air temperature, } \\
\text { relative humidity, illuminance, air velocity } \\
\text { and noise level. Longitudinal study (local): } \\
\text { temperature (and humidity) }\end{array}$ \\
\hline \multirow[t]{2}{*}{ Survey } & Background survey & Transverse questionnaire; \\
\hline & once per building & longitudinal questionnaire \\
\hline \multirow[t]{2}{*}{ Subject pool } & 4 to 100 people per & 38 (33) people \\
\hline & building occupant population & \\
\hline \multirow[t]{2}{*}{ Duration and frequency } & Within 12 months & Once each month and four times per day \\
\hline & & over 2-12 months \\
\hline
\end{tabular}

indoor climate, health and personal details. Completed questionnaires were returned by 40 per cent (352) of the subjects. A transverse questionnaire was also administered monthly to a subset of persons for up to a year. This was accompanied by detailed physical measurements that included $\mathrm{CO}_{2}$ concentration, globe temperature, air temperature, relative humidity, illuminance, air velocity and noise level. A longitudinal questionnaire was then filled in up to four times a day by 33 persons in all buildings. The temperature (and in some cases the relative humidity) close to the subject was recorded by a miniature data logger.

The comfort vote was rated within a seven-point scale. Additionally a five-point preference scale was used. Topics were temperature, air movement, humidity, lighting, noise, air quality, overall comfort and perceived productivity. In the transverse questionnaire a six-point scale for the rating of overall comfort was used. Details of clothing and metabolic rate were also collected using shortened versions of the clothing and activity descriptions from the longitudinal study. The clo value was calculated from standard tables, including a value for the chair. For evaluating the metabolic rate, activities over the previous hour were recorded. The weighted mean metabolic rate was calculated for all the reported activities. The actuation of controls of doors, heating, air conditioning, windows, blinds, lights, fans and so on at the time of the survey was also taken into account in the analysis of occupants' behaviour. In the French survey, an electronic form of the questionnaire was used frequently. Some statistical analysis of environmental data (for example, standard deviations) had been incorporated into the self-controlled analysis, which could be further developed in the future.

During the PROBE (Post-occupancy Review of Buildings and their Engineering) survey, about 20 buildings with interesting technical features, typically completed between two and five years previously, were investigated (PROBE, 1999; Bordass and Leaman, 2004) (Table 7.6). A pre-visit questionnaire of about five pages was handed out to the facilities managers to get information on the building, its operation and its utility consumption, but this was seldom filled in. The survey method that was used in the PROBE study was first developed and used in the 1980s by BUS in a comprehensive study on sick building 
TABLE 7.6 Field experiment methodology of the PROBE project

\begin{tabular}{lll}
\hline Physical measurements & BACKGROUND STUDY & DETAILED STUDY \\
Paper survey & $\begin{array}{l}\text { Spot measurements of light, } \\
\text { temperature and relative humidity }\end{array}$ & $\begin{array}{l}\text { Light, temperature, relative } \\
\text { humidity, electricity and } \\
\text { heat supply, pressure tests } \\
\text { Detailed paper questionnaire }\end{array}$ \\
& $\begin{array}{l}\text { Pre-visit questionnaire for } \\
\text { facilities managers } \\
\text { Background survey: } \\
\text { once per building } \\
\text { One person }\end{array}$ & \\
Subject pool & Some weeks & $\begin{array}{l}\text { Approximately 100 } \\
\text { persons/building } \\
\text { Once during one day }\end{array}$ \\
\hline Duration and frequency &
\end{tabular}

syndrome. An energy assessment spreadsheet was developed to prepare benchmarks of buildings. This was further developed into the CIBSE TM22 energy survey method in 1998 together with associated software. For PROBE the questionnaire was reduced in length to be speedy, easy and attractive to use and analyse. The occupant questionnaire consisted of about 40-50 variables within 12 topics that covered personal statistics, overall building aspects, individual control, speed and effectiveness of management response after complaints have been made, temperature, air movement, air quality, lighting, noise, overall comfort, health, productivity at work and some site specific questions. Most of the questions had to be answered within a seven-point 'Gregory' scale and space for personal comments on specific and general issues was provided. No questions about occupations were included because of objections by most building managers. Only one question on health and self-estimated productivity was included. Recently questions about cleaning and furniture were added. A shorter secondary questionnaire was given to special user groups, most commonly students in educational buildings.

The questionnaire was typically administered to a sample of 100-125 permanent staff or to everybody in buildings with less than 100 occupants. The sample size was important for statistical validity and to permit analysis of sub-samples within a building. The return rate was typically above 90 per cent due to the questionnaire being personally distributed by BUS members, thus giving occupants an opportunity for personal discussion. They also received all relevant information about the purpose and date of the survey in advance. The questionnaires were collected on the same day.

The analysis included two summary indexes: one based on comfort, compiled from scores for perceived summer and winter temperature and air quality, lighting, noise and overall comfort; the other based on satisfaction, using scores for design, needs, productivity and health. Recently a third index was formed at the request of clients to combine the first and second.

Spot measurements of light, temperature, relative humidity, electricity and heat supply were taken at the first site visit. Sometimes data were available from site management or independent monitoring. Pressure tests were conducted due to air tightness problems in many of the buildings. Each building was then benchmarked against a broader data set. 
TABLE 7.7 Field experiment methodology of the ProKlima project

\begin{tabular}{|c|c|c|}
\hline & BACKGROUND STUDY & DETAILED STUDY \\
\hline Physical measurements & $\begin{array}{l}\text { Indoor air quality, noises, } \\
\text { thermal comfort parameters } \\
\text { (every } 15 \text { minutes), light, } \\
\text { ergonomics of workplaces }\end{array}$ & $\begin{array}{l}\text { Indoor air quality, noises, } \\
\text { thermal comfort parameters, } \\
\text { light, medical investigations, } \\
\text { test of concentration }\end{array}$ \\
\hline Survey & Background survey & Detailed questionnaire \\
\hline Subject pool & At least 200 persons & 120 persons per building \\
\hline Duration and frequency & $\begin{array}{l}\text { Investigations took place } \\
\text { every day during one week, } \\
\text { survey was conducted once }\end{array}$ & $\begin{array}{l}\text { Several weeks with building } \\
\text { investigations, physical } \\
\text { measurements, medical } \\
\text { investigations and survey }\end{array}$ \\
\hline
\end{tabular}

The benchmarks are available and largely published or available under licence (Leaman and Bordass, 2001).

For the ProKlima project, all participating buildings had to have more than 200 occupants undertaking 'typical' office work (Table 7.7). Also no buildings with changes in construction during the previous two years were allowed to participate. Eight of the buildings had different types of air conditioning and six were naturally ventilated. 1500 workplaces were analysed with the same number of occupants being questioned and medically investigated. Indoor air quality, noises, thermal comfort parameters and light were measured during the study. Temperatures and humidity were measured at one height $(1.10 \mathrm{~m})$ over a period of 15 minutes in each building. Tests of concentration (Bordass and Leaman, 2004) were conducted at the computer. Psychological factors were also considered to have influence. After having asked all occupants in the building, a sample of 120 people per building was chosen (60 subjects with symptoms, 60 without symptoms) and measurements were taken at their individual workplaces. Paper questionnaires were distributed that included seven pages of questions about physical perceptions, health, well-being, indoor climate (including odours, light, noise, temperature), satisfaction with work and personal statistics. The questions about the indoor climate also included five-point scales about satisfaction and its importance for general well-being. The ability of individuals to influence indoor climate conditions had to be answered by 'yes' or 'no'. For evaluating sensory aspects as well as the indoor climate, a new procedure of questions was developed and validated for this study. The return rate was between 73 and 90 per cent per building.

During the HOPE project, 64 office buildings (and about 111 dwellings) in nine countries were investigated (HOPE, 2006) (Table 7.8). The buildings that were included in the study were not distributed representatively among the various European climates. The main criterion for each building to be included in the study was that access to basic information on design, building fabric, services and so on, was available. Further, reliable information about energy use for a minimum of 12 months was required to provide specific energy consumption data, including climate data from locations reasonably close to each building. About 75 per cent of the buildings showed a low energy standard based 
TABLE 7.8 Field experiment methodology of the HOPE project

\begin{tabular}{lll}
\hline & BACKGROUND STUDY & DETAILED STUDY \\
\hline Physical measurements & Energy use collected & VOCs, asbestos, $\mathrm{NO}_{\mathrm{x}^{\prime}}$ \\
& for several years & $\mathrm{CO}_{2}$ and radon \\
Survey & Building checklist & Questionnaire \\
Subject pool & & On average 90 per building \\
Duration and frequency & Once \\
\hline
\end{tabular}

on regular records in buildings or energy bills, which were collected for several years and then averaged. No correction was made for the different climate regions.

At a minimum, 50 subjects per building were required for the survey. Only buildings without changes in technology or architecture for a minimum of one year prior to the start of the study were admitted. For the more detailed study, no major renovation planned before autumn 2004 was allowed either. The questionnaires focused on occupants' satisfaction in terms of comfort and their perceived health within the building. The questionnaire was prepared especially for the HOPE project. About 420 variables were gathered in each office building and approximately 6000 valid questionnaires were collected for analysis. Overall comfort was evaluated by equally taking into account the parameters of temperature and its variability, noise from the outside and from the building itself, natural and artificial lighting, and various criteria related to the air quality. These comfort parameters had to be rated for the summer and for the winter within one survey using a seven-point scale from satisfactory to unsatisfactory. Additional questions about possible control of the indoor environment were separately asked for temperature, ventilation, shading from the sun, lighting and noise. Additional measurements of volatile organic compounds (VOCs), asbestos, nitrogen oxides $\left(\mathrm{NO}_{\mathrm{x}}\right), \mathrm{CO}_{2}$ and radon were also taken in the buildings.

To date, analysis of the data has focused on indoor environment quality and general building characteristics. Qualitative analysis involves sorting the buildings into 'best' and 'worst' categories and looking at the differences between them. All variables used in the study are mean values for each building. The building-averaged data were collected and compared, looking for correlations between building characteristics and perceived comfort and health. The aggregation method used for comfort variables assumes that all criteria - such as temperature, noise, light and air quality - have the same weight for the perception of overall comfort and health. The classification made for the study was not intended to be mandatory (Roulet et al, 2006a).

The CBE in Berkeley (http://cbe.berkeley.edu/research/publications.htm) have surveyed 142 commercial buildings (23,450 people) since the beginning of their project (Table 7.9). The core survey focuses on seven key areas of the indoor environment: office layout, office furnishing, thermal comfort, indoor air quality, lighting, acoustics, and building cleanliness and maintenance. The CBE has also developed additional question sets to gather information on specific aspects of the workplace environment. Examples of optional modules include way-finding, safety and security, operable windows, shading systems, floor diffusers and washrooms. Other modules can be optionally developed and included to investigate additional topics. 
TABLE 7.9 Field experiment methodology of the CBE

\begin{tabular}{|c|c|c|}
\hline & BACKGROUND STUDY & DETAILED STUDY \\
\hline Physical measurements & & $\begin{array}{l}\text { Depending on the study, } \\
\text { basically none }\end{array}$ \\
\hline Web survey & & $\begin{array}{l}\text { Core questionnaire, } \\
\text { additional modules }\end{array}$ \\
\hline Subject pool & & $\begin{array}{l}\text { All building occupants, } \\
\text { depending on client }\end{array}$ \\
\hline Duration and frequency & & $\begin{array}{l}\text { 5-12 minutes, open } \\
\text { for } 1-2 \text { weeks }\end{array}$ \\
\hline
\end{tabular}

The survey is web-based and offered on the CBE server in different languages. The questionnaire can be answered within 5-12 minutes depending on the number of branching questions, whenever dissatisfaction is indicated. Ratings have to be given within a seven-point scale. The survey is open for approximately two weeks, sometimes combined with a reminder via email. Response rates range from 27 to 88 per cent, with an average of about 50 per cent. The questions and modules have been kept consistent over the years and data are collected in a SOL-Server database. Thus a broad analysis and comparison between buildings is possible. Self-generated reports are available immediately after a survey via a password-protected website. Generally no physical measurements are taken and the buildings are not inspected before or during the survey.

\section{PRELIMINARY CONCLUSIONS FROM THE STUDIES}

A lot of field studies have been performed over recent decades focusing on different issues and applying different methods of post-occupancy evaluation. In contrast to laboratory experiments, they gave a strong emphasis to a broad range of building- and workplace-related parameters - for example, ventilation strategy and technological features for energy efficiency - and their influence on thermal comfort. Despite the fact that field studies and laboratory experiments are based on different research methodologies, existing scales and measurement procedures of laboratory studies that are also part of current standards were used frequently (Brager and de Dear, 1997), especially for collecting votes on thermal comfort. Due to the growing awareness of the complexity of the issues, each project has developed additional questions with changing rating scales (both even and uneven, from three-point to seven-point). The spectrum of parameters to be investigated has also grown: office layout, workload, noises, light and more have been added to find out whether and how strongly they correlate with other environmental parameters.

By contrast, most of the studies concentrated on one, or at least on a reduced number of, specific topics within the wide range of possible analyses. This is due to the large amount of data that can be collected and the restricted manpower of the research teams. Occupant surveys are mostly an economical compromise between the objectives of a study, the needs of respondents (question-answering ability), data management, data analysis and statistical validity. 
The statistical analysis in the occupant surveys considered P-values of less than 5 per cent $(\mathrm{p} 0.05)$ to be significant. In addition to frequency distributions, mean values and correlations and in some studies also multiple regression analyses and analyses of variance were generally calculated. Though building and occupant samples were not the same and different rating scales, measurements and procedures for the analyses were used, similar results were frequently obtained in comparable studies. This is particularly true for aspects such as the importance of having individual control of the indoor climate at the workplace, the low relevance of satisfaction with light for overall satisfaction with the workplace, and the rating of the noise level in correlation with the source and surroundings (PROBE, 1999; Roulet et al, 2006b; Gossauer et al, 2006).

\section{APPROACHING OVERALL COMFORT AND THERMAL COMFORT IN SUMMER BY NEW FIELD STUDIES}

Since January 2004 a post-occupancy study has been carried out in 16 German office buildings (Gossauer et al, 2006). Within the study overall comfort at the workplace and its weighted influences by thermal, visual and acoustic comfort parameters, indoor air quality and the office layout are examined. The study also considers different influences on perceived health at work and the impact of work-related factors on satisfaction and perceived productivity. Approximately 70 questions have to be answered within a five-point Likert scale, once in winter (between the middle of January and the middle of March) and once in summer (in August or September). Thus, seasonal climate influences on the occupants' judgement, particularly on temperature and lighting votes, are taken into account.

For the study, a modified version of the CBE questionnaire was used that had been previously adopted in a survey in nine office buildings of the German Railway Company (DB Netz AG) (www.enerkenn.de). A copy of the modified questionnaire can be found in Voss et al (2005).

The survey was carried out anonymously with a sample size of 30-100 randomly chosen people per building (depending on the size of the building). An average return rate of more than 80 per cent was achieved by handing out paper questionnaires personally to the participants. Approximately 1400 questionnaires were included in the multivariate statistical analysis that began in June 2006.

Additionally, room temperatures and humidity were measured with portable data loggers on the day of each survey. In some of the buildings, more data (for example, continuously logged room temperatures, opening times of windows and indoor air quality) are available from different monitoring campaigns and will be used for further evaluation. Analysis of the occupants' responses is carried out with the statistical software program SPSS (Statistical Packages for the Social Sciences, Version 11.5 and 13.0). It includes the calculation of mean values, frequency distributions and correlation values, as well as a regression analysis for dependent factors. Furthermore the correlations between independent factors are considered, for example between the general satisfaction and individual satisfaction parameters. To identify significant differences in the ratings between summer and winter, an analysis of variance was carried out. The hypotheses were statistically tested with a two-tailed alpha level of 0.05 ; the different sample sizes 


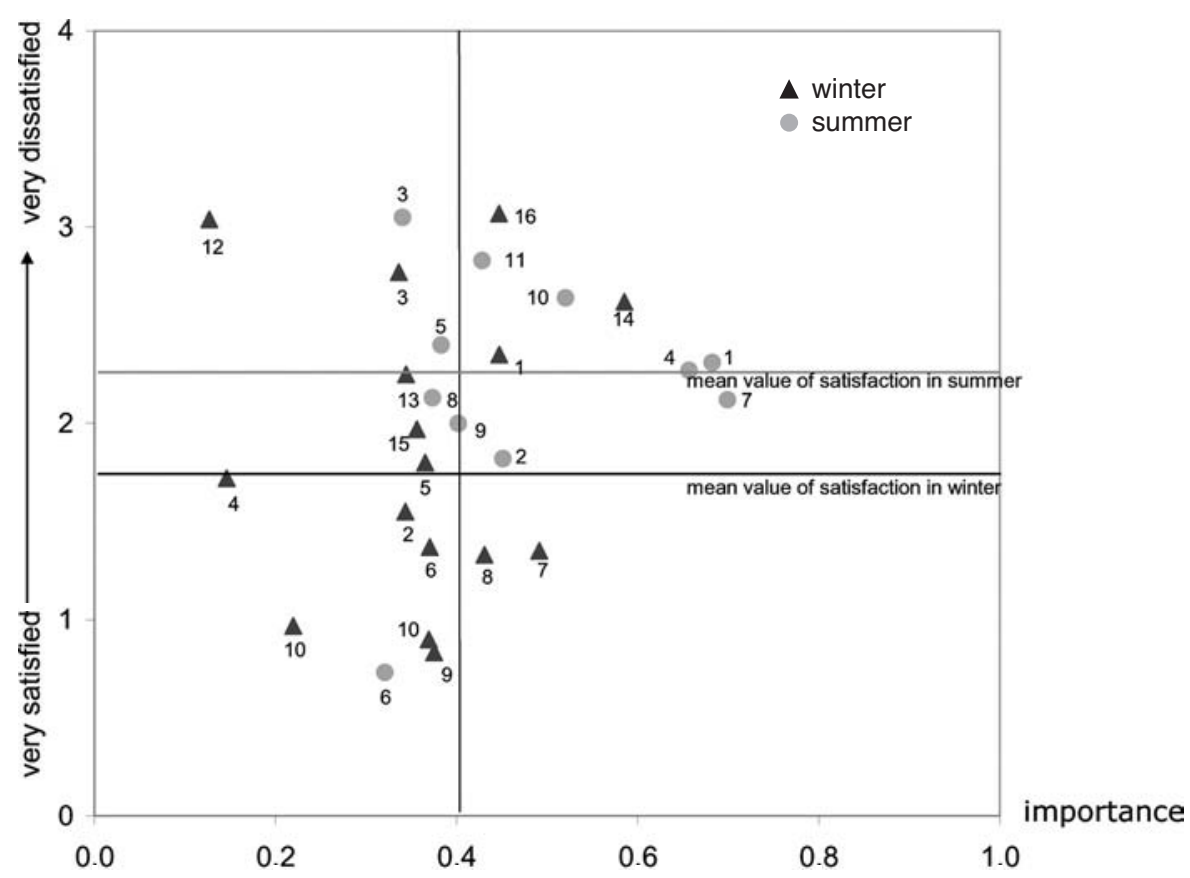

Note: The different numbers refer to the buildings in which the surveys took place. Field A (lower left sector): occupants are satisfied with the parameter but the weighting calculation shows that it is less important for the general satisfaction with the workplace. Field B (lower right sector): occupants are satisfied with the parameter and it is important for the general satisfaction with the workplace. Field $C$ (upper left sector): occupants are dissatisfied with the parameter but it is of less importance for the general satisfaction with the workplace. Field D (upper right sector): occupants are dissatisfied with the parameter and it is very important for the general satisfaction with the workplace.

Source: Gossauer et al (2006)

FIGURE 7.5 Correlation between mean satisfaction with temperature and weighted importance of temperature for general satisfaction with the workplace (Spearman correlation)

and the occasional imparity of variance were considered as well. A cluster analysis was used to identify possible groupings of building characteristics.

For the evaluation, the extent to which individual satisfaction parameters influence general judgement of the workplace can be correlated with general satisfaction of the workplace. This leads to weighted values of the importance of each parameter in relation to the general satisfaction. This weighting procedure proved to be more reliable when compared to the occupants' judgements because occupants mostly tend to choose the categories 'important' or 'very important' if asked directly. Figure 7.5 illustrates the weighting of the satisfaction with temperature for the general satisfaction with the workplace. It can be seen that in summer dissatisfaction with room temperature is generally higher than in winter, and also the importance of this parameter for general satisfaction with the workplace is not necessarily exclusively dependent on the grade of dissatisfaction.

One aim of this study is to propose limits for the different comfort parameters concerning workplace satisfaction. Further objectives are to suggest standards for 
questions and scales and the statistical analysis for the evaluation of overall comfort. Thus a tool for a more straightforward building assessment can be provided. An innovation for this kind of study is the consistent seasonal evaluation of all buildings and the accurate evaluation of seasonal differences and coherencies between different parameters by means of multiple regression analysis and cluster analysis. A model for the validation of the item structure is currently being calculated and thus confirmation of the strength of various correlations will be available soon.

Another field survey was carried out in an office and laboratory building in Karlsruhe during July 2005 in order to compare measurements and subjective votes on thermal comfort in a non air-conditioned indoor environment under German climate conditions (Wagner et al, 2006). Over a period of four weeks, 50 subjects filled in questionnaires twice a day every Tuesday and Thursday, and accompanying measurements were carried out at the workplaces. The actual votes on thermal sensation did not correspond to predicted mean votes, which were calculated with measured data during the interviews, but a very good agreement was seen with adaptive comfort models. Clothing values were noticed to be different to the standard values.

\section{CONCLUSIONS}

The issue of thermal comfort at workplaces has gained much importance since the early 1990s. The paper has shown that post-occupancy evaluation in field studies has had a major influence on new understandings, already leading to modified standards (ASHRAE) and new proposals for standards in Europe. These standards, introducing adaptive comfort models, are particularly important for buildings relying on passive cooling strategies in order to meet increasing requirements for energy efficiency (for example, the European Energy Performance of Buildings Directive of 2001). Since the very hot summer of 2003 in Europe at least, upper temperature limits for thermal comfort have been widely discussed (Pfafferott et al, 2004). Unlike existing comfort standards that are derived from laboratory experiments, the adaptive models are derived from field studies and have proved that thermal comfort in non air-conditioned buildings depends more on external climate conditions than on the expectations of building occupants.

Field studies also reveal that the occupants' perceptions of the indoor environment are influenced by numerous parameters. These include building- and workspace-related parameters as well as contextual variables. In contrast to laboratory experiments, boundary conditions cannot be controlled in field studies so there still remain many open questions regarding the 'definition' of the key parameters for overall satisfaction with the workplace, well-being and productivity. Furthermore, little is known about the impact of interrelations between these parameters.

It is interesting that recent experiments in climate chambers have started to implement more 'real building characteristics' in order to converge with 'field experiment facilities'. The well-known climate chambers of the International Centre for Indoor Environment and Energy in Copenhagen, for example, are expanding and have been renamed as 'indoor environment chambers' with the purpose of doing research on air quality, thermal comfort, health and productivity under a wide variety of indoor environment conditions and moderate building energy consumption (Toftum et al, 2004). 
The climate chamber of the CBE in Berkeley is a standard office room equipped with all features to control the indoor climate. Nevertheless, many relevant factors that influence perception at workplaces are still not captured, such as typical noises, normal work routines, social surroundings and so on.

One of the major shortcomings of the current status of buildings surveys is a lack of transparency and compliance of methodologies applied for performing the studies and analysing results. Therefore it is easy to understand why the ASHRAE scale, and sometimes the Bedford scale, is in use for most thermal comfort evaluations - despite the fact that field studies for comfort perception or more specific purposes might need different voting procedures. Restricted access to questionnaires, databases or to descriptions of survey procedures and data analysis, prevents a thorough comparison of different studies and their results. A particular problem is the translation of questionnaires into different languages. In the European SCATs project all questionnaires were translated back into English (original language) after having been translated into the languages of the participating countries. This allowed researchers to verify that all details had been interpreted correctly. Cultural influences that give different meanings to the same word in different languages add to this problem.

Methodologies reveal that items like health (Bischof et al, 2003), comfort and productivity are not interpreted in similar ways in the different studies. Further, scales are interpreted differently and the temporal assignment of measurements and votes, for example for perceived indoor temperature, remains unclear in some cases. Another problem is the number of buildings chosen for a particular study. When only one building is studied the survey is not representative, but when a high number of buildings are studied, the number of data to be gathered and analysed increases rapidly. There is a danger that the original intention of field studies to analyse interrelations between different parameters influencing overall satisfaction is being abandoned because the vast amount of data cannot be analysed thoroughly.

The aim of our recent study was therefore to choose a representative sample of buildings and occupant samples, to be able to analyse the overall dependencies on general satisfaction with the workplace and the weighting of its influencing factors (Gossauer et al, 2006). Not all of them do have the same weight in terms of impact on satisfaction, even though this is often assumed. A more standardized data analysis procedure should be followed in the future in order to find the most relevant parameters for comfort, well-being, productivity and health. Important aspects are:

- ratings between different buildings and countries;

- social-cultural, workspace or building-related influences on the ratings;

- groups of buildings with similar characteristics, for example to be found by cluster analysis; and

- sample sizes, gender or seasonal influences on thermal comfort and other comfort parameters.

For further post-occupancy evaluation it is important to have consistent and worldwide available methodologies with validated question modules (such as from the CBE) and with 
detailed instructions. Methods applied so far for assessing comfort or productivity in running buildings should be critically reviewed for the purpose of modifying existing standards. A high response rate is another important criterion for selection. The studies showed a wide range of response rates, for example, depending on how the questionnaires were distributed. Accessible databases should be provided (like the ASHRAE database), which are of high value for future scientific research.

In a next step, post-occupancy evaluation could be integrated into facility management of commercial buildings to enable more straightforward building performance assessments. Surveys can be used as a diagnostic tool for buildings if they are easy and quick to handle for occupants and give quick and understandable feedback to building managers. The amount of time needed for filling in questionnaires is probably the most crucial issue for gaining a broad acceptance by building managers because it is directly related to the specific economic performance of a person. However, personnel costs usually form the bulk of company expenditure and so should justify the expense of improving the well-being of occupants in their workplace. Appropriate tools could be developed as derivates of research tools. A good example is the CBE survey that asks only for detailed answers to questions about the causes of dissatisfaction.

\section{AUTHOR CONTACT DETAILS}

Elke Gossauer, Building Physics and Technical Building Services, University of Karlsruhe, Englerstr. 7, 76131

Karlsruhe, Germany

Email: info@fbta.uni-karlsruhe.de

Andreas Wagner, Building Physics and Technical Building Services, University of Karlsruhe, Englerstr. 7, 76131

Karlsruhe, Germany

Email: info@fbta.uni-karlsruhe.de

\section{REFERENCES AND FURTHER READING}

ASHRAE (American Society of Heating, Refrigerating and Air-conditioning Engineers) (2004) 'ASHRAE 55 Standard 55 -

Thermal environmental conditions for human occupancy', ASHRAE Inc., Atlanta, GA

Bedford, T. (1936) 'The warmth factor in comfort at work', Rep. Industr. Hlth. Res. Bd., No. 76, London

Bischof, W., Bullinger-Naber, M., Kruppa, B., Hans Müller, B. and Schwab, R. (2003) Expositionen und

gesundheitsschädliche Beeinträchtigungen in Bürogebäuden, Ergebnisse des ProKlimA-Projektes, Fraunhofer IBR Verlag,

Stuttgart

Bordass, B. and Leaman, A. (2004) 'Closing the loop - post-occupancy evaluation: Next steps - PROBE: How it happened, what it found, and did it get us anywhere?', Proceedings of Cumberland Lodge Conference, Windsor

Bordass, B. and Leaman, A. (2005) 'Making feedback and post-occupancy evaluation routine 1: A portfolio of feedback techniques', Building Research and Information, vol 33, no 4, pp347-352

Brager, G. S. and de Dear, R. (1997) Developing an Adaptive Model of Thermal Comfort and Preference, final report, ASHRAE RP-884, Berkeley, CA

Brager, G. S. and de Dear, R. (1998) 'Thermal adaptation in the built environment: A literature review', Energy and Buildings, vol 27, pp83-96 
Brager, G. S. and de Dear, R. J. (2003) 'Historical and cultural influences on comfort expectations', in Cole, R. and Lorsch, R. (eds) Buildings, Culture and Environment: Informing Local and Global Practices, Section II, Chapter 11, Blackwell, London

Brager, G. S., Paliaga, G. and de Dear, R. (2004) 'Operable windows, personal control and occupant comfort', ASHRAE

Transactions, vol 110, Part 2, pp17-35

BREEAM, www.breeam.org, accessed June 2006

Canter, D., Stringer, P. et al (1975) Environmental Interaction, Surrey UP, London

Chappells, H. and Stove, E. (2005) 'Debating the future of comfort: environmental sustainability, energy consumption and the indoor environment', Building Research \& Information, vol 33, no 1, pp32-40

Cooper, G. (1982) 'Comfort theory and practice: Barriers to the conservation of energy by building occupants', Applied Energy, vol 11, pp243-288

Cooper, I. (2001) 'Post-occupancy evaluation: Where are you?', Building Research and Information, vol 29, no 2, pp158-163

de Dear, R. (2004) 'Thermal comfort in practice', Indoor Air, vol 14, no 7, pp32-39

de Dear, R., Brager, G. S. and Cooper, D. (1997) 'Developing, an adaptive model of thermal comfort and preference, Final Report, ASHRAE, RP-884

Eriksson, N. (1996) 'Psychological factors and the "sick building syndrome". A case-referent study', Proceedings of Indoor Air, vol 6, no 2, pp101-110

Fang, L., Wyon, D. P., Clausen, G. and Fanger, P. O. (2002) ‘Sick building syndrome symptoms and performance in a field study at different levels of temperature and humidity', Proceedings of Indoor Air, Monterey, vol 3, pp466-471

Fanger, P. 0. (1970) Thermal Comfort. Analysis and Applications in Environmental Engineering, McGraw-Hill, New York

Fanger, P. O. (1988) 'A comfort equation for indoor air quality and ventilation', Proceedings of Healthy Buildings, vol 1, pp39-51

Gagge, A. P., Forbelets, A. P. and Berglund, L. G. (1986) 'A standard predictive index of human response to the thermal environment', ASHRAE Transactions, vol 92, no 2b, pp709-731

Gossauer, E., Leonhart, R. and Wagner, A. (2006) 'Nutzerzufriedenheit am Arbeitsplatz- eine Untersuchung in sechzehn Bürogebäuden', submitted for publication

Hellwig, R. T. (2005) Thermische Behaglichkeit - Unterschiede zwischen frei und mechanisch belüfteten Gebäuden aus Nutzersicht, Dissertation, University of Munich, Munich

HOPE (2006) http://hope.epfl.ch, accessed June 2006

Humphreys, M. A. (1994) 'Field studies and climate chamber experiments in thermal comfort research', in Oseland, N. and Humphreys, M. (eds) Thermal Comfort: Past, Present and Future, Building Research Establishment, Watford, pp52-69

Humphreys, M. A. (2005) 'Quantifying occupant comfort: Are combined indices of the indoor environment practicable?', Building Research \& Information, vol 33, no 4, pp317-325

Humphreys, M. A. and Nicol, J. F. (2000) 'The effects of measurements and formulation error on thermal comfort indices in the ASHRAE database of field studies', ASHRAE Transactions, vol 206, no 2, pp493-502

ISO 7730 (2005) prEN ISO 7730: Ergonomics of Thermal Environment, Beuth Verlag, Berlin

Kaczmarczyk, L., Zeng, O., Melikov, A. and Fanger, P. O. (2002) 'The effect of a personalized ventilation system on perceived air quality and SBS symptoms', Proceedings of Indoor Air, vol 4, pp1042-1047

Kröling, P. (1985) Gesundheits- und Befindlichkeitsstörungen in klimatisierten Gebäuden. Vergleichende Untersuchung zum 'building illness' Syndrom, Zuckerschwerdt, Munich

Leaman, A. and Bordass, B. (1999) 'Productivity in buildings: The 'killer' variables', Building Research and Information, vol 27. no 1, pp4-19

Leaman, A. and Bordass, B (2001) 'Assessing building performance in use 4: The PROBE occupant surveys and their implications', Building Research and Information, vol 29, no 2, pp129-143

McCartney, K. J. and Nicol, J. F. (2002) 'Developing an adaptive control algorithm for Europe', Energy and Buildings, vol 34, pp623-635 


\section{Post-occupancy Evaluation and Thermal Comfort 175}

Mendell, M. J. (1993) 'Non-specific symptoms in office workers: A review and summary of the epidemiologic literature', Proceedings in Indoor Air, vol 3, no 4, pp227-236

Nicol, J. F. and Humphreys, M. A. (1973) 'Thermal comfort as part of a self-regulating system', Building Research and Practice (J. ClB), vol 6, no 3, pp191-197

Nicol, J. F. and Humphreys, M. A. (2002) 'Adaptive thermal comfort and sustainable thermal standards for buildings', Energy and Buildings, vol 34, pp563-572

Nicol, J. F. and Kessler, M. (1998) 'Perception of comfort in relation to weather and adaptive opportunities', ASHRAE Technical Data Bulletin, vol 104, no 1, pp1005-1017

Nicol, J. F. and McCartney, K. (2000) Smart Controls and Thermal Comfort Project, SCATs final report, Oxford Brookes University, Oxford

Nicol, J. F. and Roaf, S. (2005) 'Post occupancy evaluation and field studies of thermal comfort', Building Research and Information, vol 33, no 4, pp338-346

Nikolopoulou, M. and Steems, K. (2003) 'Thermal comfort and psychological adaption as a guide for designing urban spaces', Energy and Buildings, vol 35, pp95-101

Pfafferott, J., Herkel, S. and Wagner, A. (2004) 'Müssen unsere Bürogebäude klimatisiert werden?', HLH - Lüftung/ Klima, Heizung/ Sanitär, Gebäudetechnik, vol 3, pp24-30

PROBE (1999) PROBE Strategic Conclusion, Final Report 4, Center for the Built Environment, Berkeley, CA

Roulet, C. A., Flourentzou, F., Foradini, F., Bluyssen, P. H., Cox, C. H. and Aizlewood, C. (2006a) 'Multi-criteria analysis of health, comfort and energy efficiency of buildings', Building Research and Information, vol 34, no 5, pp475-482

Roulet, C. A., Johner, N., Foradini, F., Bluyssen, P. H., Cox, C. H., Oliveria Fernandes, E., Müller, B. and Aizlewood, C. (2006b) 'Perceived health and comfort in European buildings in relation with energy use and other building characteristics', Building Research and Information, vol 34, no 5, pp467-474

Rowe, D. (1998) 'Occupant interaction with a mixed media thermal climate control system improves comfort and saves energy', AlRAH Meeting, Sydney

Thommen, J. P. (2002) Management \& Organisation, Konzepte, Instrumente, Umsetzung, Versus Verlag, Zürich

Toftum, J., Langkilde, G. and Fanger, P. O. (2004) 'New indoor environment chambers and field experiment offices for research on human comfort, health and productivity at moderate energy expenditure', Energy and Buildings, vol 36, pp889-903

van der Linden, A. C. and Boerstra, A. (2006) 'Adaptive temperature limits: A new guideline in the Netherlands. A new approach for the assessment of building performance with respect to thermal indoor climate', Energy and Buildings, vol 38, pp8-17

Voss, K., Herkel, S., Löhnert, G., Wagner, A. and Wambsganß, M. (2005) Bürogebäude mit Zukunft - Konzepte, Erfahrungen, Analysen, TÜV-Verlag, Köln

Wagner, A., Moosmann, C., Gropp, T. and Gossauer, E. (2006) 'Thermal comfort under summer climate conditions: Results from a survey in an office building in Karlsruhe, Germany', Proceedings of Windsor Conference on Thermal Comfort, Windsor

Wargocki, P., Wyon, D. P., Sundell, J., Clausen, G. and Fanger, P .0. (2000) 'The effects of outdoor supply rate in an office on perceived air quality, sick building syndrome (SBS) symptoms and productivity', Indoor Air, vol 10, no 4, pp222-236

Wilson, S. and Hedge, A. (1997) The Office Environment Survey: London, Building Use Studies, London

Zagreus, L., Huizenga, C., Arens, E. and Lehrer, E. D. (2004) 'Listening to occupants: A Web-based indoor environmental quality survey', Indoor Air, vol 14, no 8, pp65-74 
